\title{
A utilização de enxertia óssea homógena proveniente dos bancos de tecidos musculoesqueléticos como alternativa para reconstrução de maxila atrófica
}

\section{The use of demineralized allogeneic bone graft from musculoskeletal tissue banks as an alternative to the reconstruction of atrophic maxilla: a case report}

\author{
Mário Jorge Souza Ferreira Filho ${ }^{1}$, Thayla Carvalho Lopes ${ }^{2}$, Raphael Carvalho e Silva ${ }^{2}$, Felipe Leite Coletti ${ }^{1}$ \\ ${ }^{1}$ Curso de Mestrado em Ciências Odontológicas, Centro Universitário da Fundação Educacional de Barretos \\ (UNIFEB) - Barretos (SP), Brasil. \\ ${ }^{2}$ Faculdade de Odontologia, Instituto Amazônia de Ensino Superior (IAES) - Manaus (AM), Brasil.
}

\begin{abstract}
Resumo
Introdução: Em decorrência de suas propriedades osteogênicas e por não proporcionar reações antigênicas, o osso autógeno é o biomaterial que melhor satisfaz as características do enxerto ideal, além de ser considerado padrão ouro e de primeira escolha pelos profissionais, porém apresenta algumas desvantagens e limitações. Objetivo: O objetivo deste trabalho foi demonstrar as aplicações, a técnica cirúrgica e viabilidade da utilização de enxerto de osso proveniente de banco de tecidos. Material e Métodos: Paciente de 46 anos, gênero masculino, procurou a clínica de Implantodontia do curso de Especialização em Implantodontia do Instituto Amazônia de Ensino Superior - IAES, com queixa de desconforto quanto à utilização de prótese parcial removível superior. Durante avaliação clínica notou-se severa reabsorção comprovada através de exame com especimetro ósseo, e nenhum achado relevante em radiografia panorâmica. Optou-se pela enxertia homógena pelas indicações de não requerer um leito doador e apresentar porções ilimitadas, diminuindo assim a morbidade de uma cirurgia já considerada traumática. Resultado: Depois de 7 meses observou-se a manutenção do volume e altura do enxerto em rebordo alveolar. Conclusão: A utilização de osso homógeno, proveniente de bancos de tecidos musculoesqueléticos, representa uma alternativa acessível e bastante vantajosa na implantodontia.
\end{abstract}

Palavras-chave: cirurgia oral; transplante homólogo; reabsorção óssea.

\begin{abstract}
Introduction: Due to its osteogenic properties and because it does not cause antigenic reactions, autologous bone is the biomaterial that best satisfies the characteristics of an ideal graft, and is considered the gold standard and first choice among professionals; however, it presents some drawbacks and limitations. Objective: The objective of this study was to demonstrate the applications, the surgical technique, and the feasibility of using bone graft from tissue banks. Material and Methods: A 46-year-old male patient sought the Implantology Clinic of the "Instituto Amazônia de Ensino Superior" - IAES complaining of discomfort in the use of upper removable partial denture. During clinical evaluation, severe resorption was observed and confirmed by examination with bone caliper. Panoramic radiography showed no relevant alterations. Homologous grafting was chosen for not requiring a donor site and presenting unlimited portions, therefore
\end{abstract}

Autor para correspondência: Mário Jorge Souza Ferreira Filho - Rua Prof. Roberto Frade Monte, 389

- Bairro Aeroporto - CEP: 14783-226 - Barretos (SP), Brasil - E-mail: dr.mfilho@gmail.com

Recebido em: 23 de abril de 2015

Aceito para publicação em: 16 de novembro de 2016

http://dx.doi.org/10.4322/1980-0029.082015 
decreasing the morbidity of a surgery considered traumatic. Results: After 7 months, maintenance of volume and height of the alveolar bone graft was observed. Conclusion: The use of autologous bone grafting from musculoskeletal tissue banks is an affordable and very advantageous alternative in implantology.

Keywords: oral surgery; homologous transplantation; bone resorption.

\section{Introdução}

Em uma reabilitação protética com implantes, um adequado volume ósseo é necessário para que se obtenha o sucesso funcional e estético (ESPOSITO et al., 2006).

$\mathrm{Na}$ odontologia moderna, a falta de osso nos rebordos alveolares tem sido um grande problema na recuperação estético-funcional dos pacientes que tenham sofrido traumatismos dentoalveolares, extrações dentárias traumáticas, ausência dentária congênita, patologias que envolvam maxila e mandíbula, além de infecções, sendo esta falta de osso uma das limitações para a reabilitação protética com implantes, por apresentar um volume ósseo inadequado para a estabilidade inicial. A falta de volume ósseo pode acarretar ainda um mau posicionamento dos implantes devido à instalação na angulação inadequada. Esta, por sua vez, comprometerá a estética, originará problemas para higienização e poderá levar à perda dos implantes (MARZOLA e PASTORI, 2006).

De acordo com Atwood (1971), a maxila sofre reabsorções mais rápidas e severas do que a mandíbula após perdas dentais, um dos motivos é que inserções musculares não estão presentes nos alvéolos maxilares e, desta forma, não há estímulo funcional após esta perda, sabe-se ainda que a reabsorção óssea é crônica, progressiva, irreversível e cumulativa, sendo mais rápida nos primeiros seis meses e continuando por toda a vida do paciente.

Para restabelecer largura e altura com a finalidade de obter uma posição ideal para a instalação de implantes dentários, são propostas várias técnicas de enxertos, que, quanto à sua origem, podem ser autógenos, quando obtidos do mesmo indivíduo, sendo este receptor e doador; isógenos, quando obtidos de outro indivíduo com mesma carga genética; homógenos, quando obtidos de indivíduos diferentes da mesma espécie com carga genética diferente; e os heterógenos, que são obtidos de outras espécies (RONDINELLI et al., 1994).

Dentre os tipos de ossos utilizados nas enxertias, o autógeno é o que possui todas as propriedades esperadas em um enxerto ideal, como a capacidade de osteogênese, osteoindução e osteocondução, e o que mostra melhores resultados, porém, apresenta limitações, como a morbidade, tempo cirúrgico, quantidade inadequada de osso na região intraoral, dificuldade técnica e maior risco de lesão neurovascular (FRIEDLANDER, 1987; GARCIA JÚNIOR et al., 2007; D'ALOJA et al., 2011).

Levandowsky Júnior (2008) relatou que, apesar da segurança proporcionada pelo osso autógeno para a correção de defeitos alveolares, é constante a busca de alternativas que eliminem ou diminuam a morbidade de uma segunda região operada.

Dentre os materiais utilizados para substituir o enxerto autógeno, o osso alógeno ou homógeno aparece como uma alternativa viável, com elevados índices de sucesso em procedimentos de regeneração óssea guiada. Além de apresentar grande aplicabilidade, é biocompatível, possui boa resposta pós-operatória, reduz o desconforto pós-operatório, não há morbidade da área doadora, é disponível em quantidades ilimitadas, possui potencial antigênico extremamente baixo e registro de segurança na odontologia (FUGAZZOTTO 1998; GOMES et al., 2006).

\section{Relato de Caso}

Paciente R. S. C., feoderma, 46 anos, gênero masculino, compareceu à clínica do curso de Especialização em Implantodontia do Instituto Amazônia de Ensino Superior - IAES, no ano de 2012. O paciente procurou a instituição de ensino com a queixa de que não conseguia se alimentar normalmente, pois sua prótese havia quebrado, e que não gostaria de usar este tipo de prótese novamente, solicitando avaliação clínica para reabilitação com implantes. Na anamnese, não foram identificadas alterações locais que contraindicassem o tratamento de reabilitação protética na região de maxila, sendo solicitados exames radiográficos para avaliar a estrutura óssea remanescente. Ao exame clínico, a maxila apresentava mucosa queratinizada (Figura 1); ao exame radiográfico, verificou-se altura de remanescente ósseo variável entre 14 e 16 mm, e extensas áreas de reabsorção 
óssea que supostamente seriam uma área de pouca espessura óssea (Figura 2).

Exames complementares, como hemograma completo, glicemia em jejum e coagulograma, foram solicitados para descartar problemas sistêmicos, demonstrando que a saúde do paciente estava em plenas condições para que fosse submetido aos procedimentos cirúrgicos. O planejamento final constituiu-se de colocação de dois blocos de osso homógeno e, após seis meses, da instalação de implantes na região anterior de maxila, optando-se ainda por preservar região posterior pela pneumatização dos seios maxilares, evitando assim a necessidade de enxertos para elevação dessas membranas, e posterior instalação de prótese implantossuportada.

Foram obtidos do Banco de Tecidos Musculoesqueléticos de Marília /SP (UNIOSS), dois blocos ósseos com as características morfo-histológicas a seguir: tecido córtico medular de joelho que possuía $20 \times 10 \times 6 \mathrm{~mm}$ e que fora processado em 14/3/2012 com validade até 19/12/2016 conservados à temperatura de $-80^{\circ} \mathrm{C}$.

No período pré-operatório, foram prescritos para o paciente dois comprimidos de amoxicilina a $500 \mathrm{mg}$, e um comprimido de dexametasona a $4 \mathrm{mg}$, uma hora antes da cirurgia. O paciente foi submetido a anestesia local infiltrativa na região vestibular e palatina com articaína $4 \%$ com epinefrina 1:100.000. Em seguida, foi realizada uma incisão do tipo envelope iniciando na região do elemento 15 à região do elemento 25 acompanhada de duas incisões relaxantes (Figura 3).

Depois do descolamento mucoperiostal do retalho (Figura 4), o bloco ósseo foi esculpido para ser adaptado ao leito receptor, de forma mais íntima possível, para propiciar o maior contato com o osso hospedeiro, sendo irrigado constantemente com solução salina fisiológica a $0,9 \%$ (Figura 5). A realização das perfurações ósseas no leito receptor foi realizada juntamente com as perfurações dos enxertos e, então, os fragmentos foram fixados em posição com seis parafusos de medidas $1,6 \times 13 \mathrm{~mm}\left(\right.$ TitaniumFix $^{\circledR}$ ) (Figura 6), promovendo a fixação do enxerto ósseo em bloco com maior estabilidade (Figura 7). Com os enxertos em posição, foram realizados desgastes para arredondar os vértices dos blocos (Figura 8), o tecido mole foi reposicionado de maneira a cobrir todo o leito operatório sem tensão e, então, realizada a síntese com sutura simples usando fio de nylon 3-0 (Figura 9).

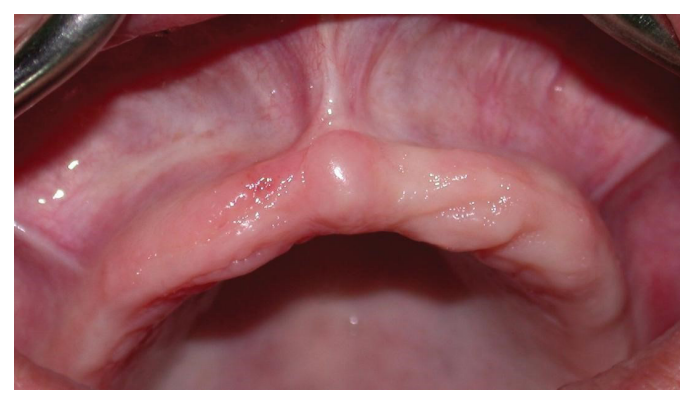

Figura 1. Aspecto inicial da mucosa.

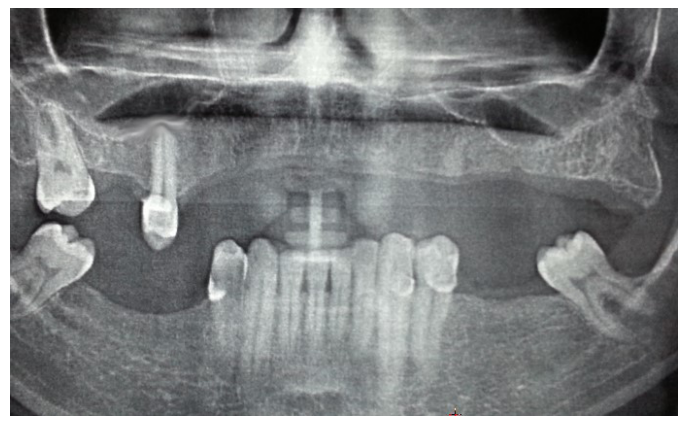

Figura 2. Radiografia inicial.

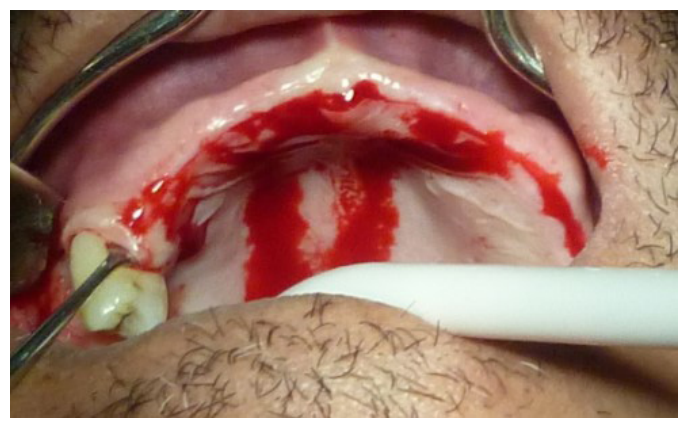

Figura 3. Incisão inicial.

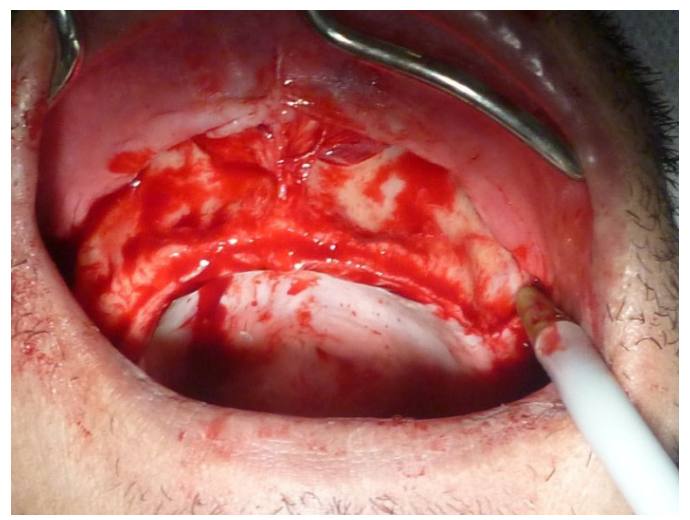

Figura 4. Retalho mucoperiostal e incisões relaxantes. 
Para o período pós-operatório, foram prescritos $500 \mathrm{mg}$ de amoxicilina de $8 \mathrm{em} 8$ horas por cinco dias, uma ampola de diprospan injetável em I.M. profundo e $500 \mathrm{mg}$ de dipirona sódica de 6 em 6 horas em caso de sensibilidade dolorosa,

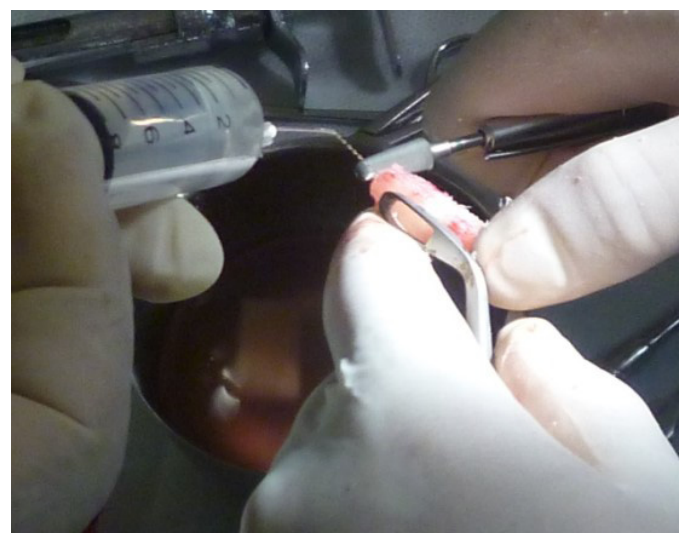

Figura 5. O bloco ósseo foi preparado com fresa, sob irrigação constante.

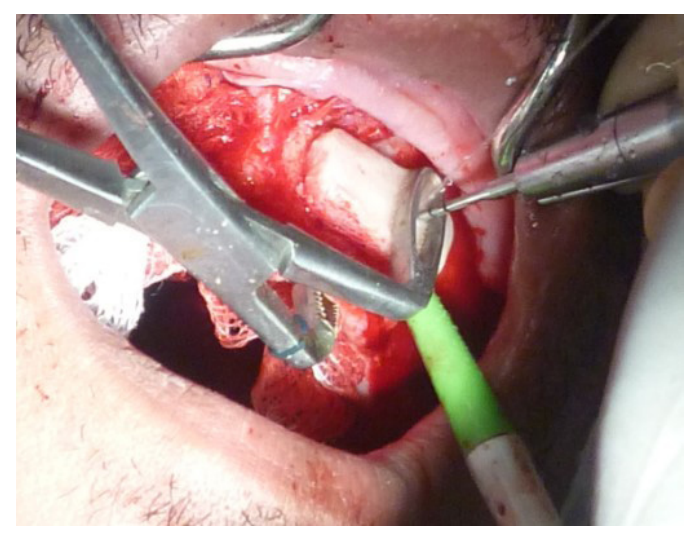

Figura 6. Perfuração do bloco.

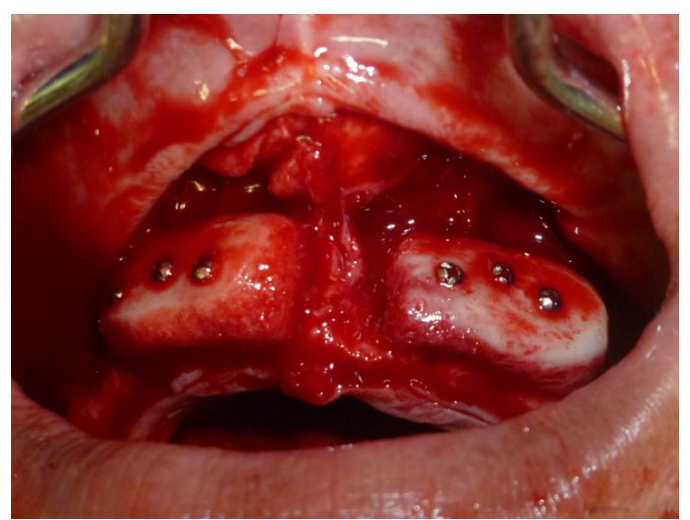

Figura 7. Fixação dos blocos ósseos. além de enxaguante bucal com clorexidina a $0,12 \%$ três vezes ao dia durante sete dias após 24 horas da cirurgia. A remoção da sutura ocorreu sete dias após a cirurgia, e o pós-operatório transcorreu dentro da normalidade, sem nenhuma intercorrência.

Sete meses após, ao retorno do paciente, foi observado que os parafusos estavam proeminentes na mucosa, indicando possível reabsorção dos blocos transplantados (Figura 10). Em exame radiográfico, observaram-se os parafusos de enxerto em posição e nenhum achado radiográfico

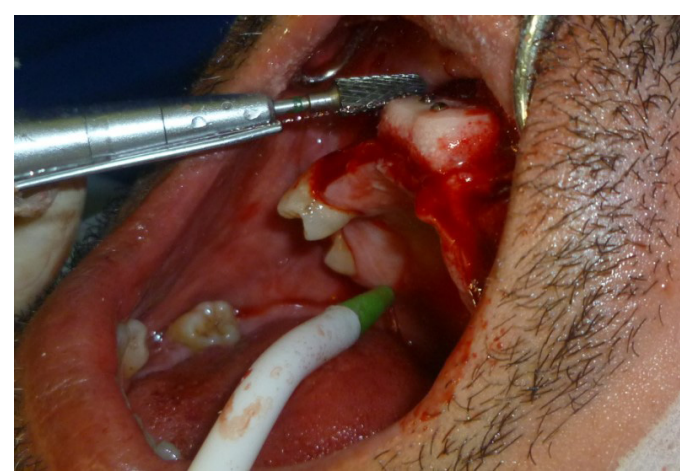

Figura 8. Desgaste de ângulos retos.

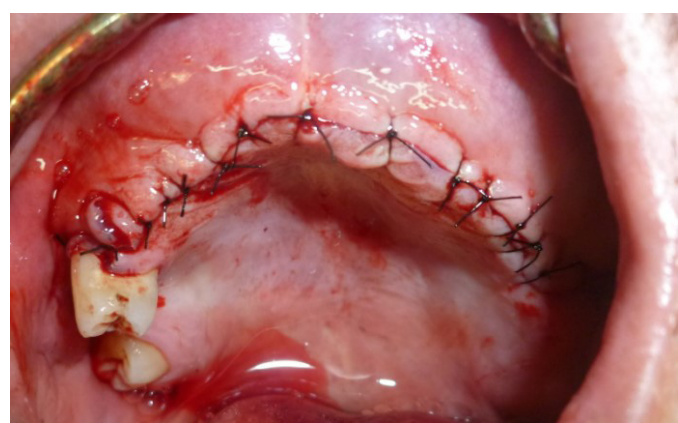

Figura 9. Síntese.

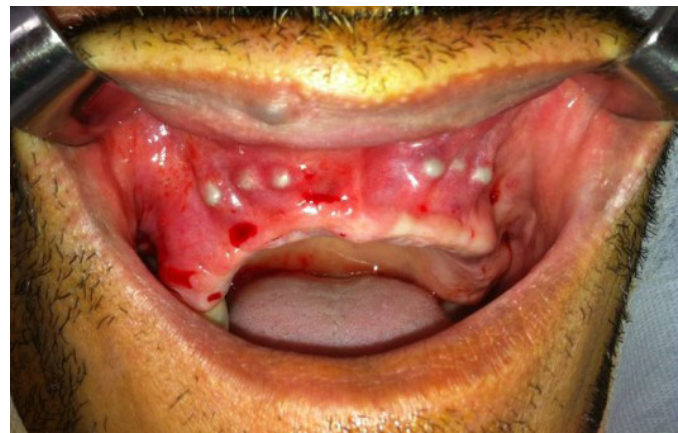

Figura 10. Aspecto após 7 meses. 


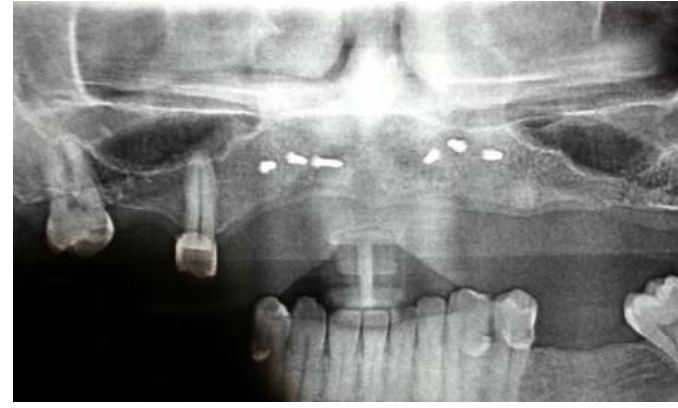

Figura 11. Radiografia pós-enxertia.

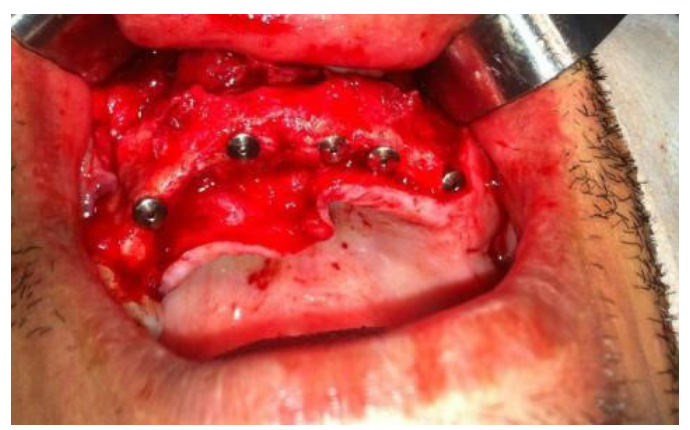

Figura 12. Implantes instalados.

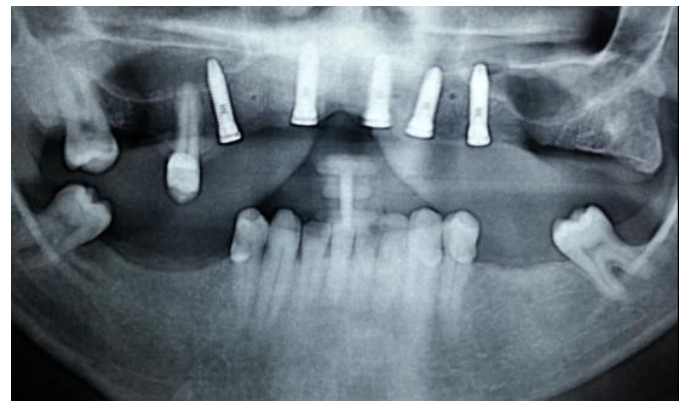

Figura 13. Radiografia final.

relevante (Figura 11). Foi então realizada a cirurgia de instalação de implantes. A medicação pré-cirúrgica, as incisões e a elevação do retalho foram semelhantes às descritas na cirurgia anterior, tomando-se o cuidado de expor os parafusos de fixação do enxerto.

A maxila anterior do paciente apresentava espessura suficiente para uma abordagem palatina dos implantes e a manutenção de uma boa espessura óssea vestibular para a manutenção dos tecidos moles e boa estética gengival. Foram realizadas as perfurações com a sequência de fresas padronizadas pelo fabricante, para instalação de cinco implantes na região anterior de maxila. Dois implantes tinham $3,75 \times 13 \mathrm{~mm}$ e três eram de $3,75 \times 15 \mathrm{~mm}\left(\right.$ TitaniumFix $^{\circledR}$ ), plataforma do tipo hexágono externo, e foram instalados nos alvéolos cirúrgicos (Figura 12). O retalho foi reposicionado e a síntese realizada. A remoção da sutura ocorreu sete dias após a cirurgia e, mais uma vez, o pós-operatório transcorreu dentro da normalidade, sem nenhuma intercorrência.

Quatro meses após, houve o contato com o paciente, que relatou satisfação com relação ao aspecto clínico final e radiograficamente pudemos visualizar a disposição final dos implantes (Figura 13).

\section{Discussão}

Os enxertos ósseos alógenos frescos e congelados têm sido utilizados como alternativa aos autógenos desde 1880, quando William MacEwen substituiu com sucesso um tecido ósseo umeral infectado por tecido ósseo tibial de outro indivíduo da mesma espécie (CHASE e HERNDON, 1955).

O enxerto homógeno conta com as vantagens de não apresentar a morbidade da área doadora, visto que este provém de outro indivíduo, é encontrado em quantidade ilimitada para uso, ajuda na diminuição do tempo operatório, ausência de cicatriz e diminuição das complicações relativas à cirurgia da área doadora. Levandowsky Júnior (2008), Garcia e Feofillof (1996) ainda indicam que as principais desvantagens do enxerto com osso homógeno são a maior imunogenicidade, menor capacidade de osteogênese e osteoindução, consolidação mais lenta, possibilidade de transmissão de doenças e maior taxa de infecção.

O osso homógeno apresenta-se como uma alternativa viável à utilização do osso autógeno (LUPOVICI, 2009; LEVANDOWSKY JÚNIOR, 2008; FUGAZZOTTO, 1998; RONDINELLI et al., 1994; GARCIA JÚNIOR et al., 2007). Podendo ser confeccionado na forma de blocos para a reconstrução de defeitos ósseos extensos dos maxilares, além do fato de ser o único substituto do osso autógeno que pode apresentar potencial osteoindutor (PETRUNGARO e AMAR, 2005). Porém, o seu uso ainda é questionado por alguns autores, que relatam uma pobre incorporação do enxerto ao leito ósseo receptor, que pode vir a comprometer o processo de osseointegração dos implantes dentários (CRANIN et al., 2003; MAZONETTO, 2009; STEVENSON, 1999). 
Enxertos homógenos perdem seus componentes celulares durante o processamento, portanto são enxertos acelulares (D'ALOJA et al., 2008; GREENSTEIN et al., 2009), no entanto a vantagem mais importante destes é que as proteínas osteoindutoras não são destruídas após a preparação, resultando em melhor formação óssea e manutenção do enxerto ósseo em longo prazo (POGREL, 1988).

Alguns autores (GARCIA e FEOFILLOF, 1996; MARZOLA e PASTORI, 2006; AMATUZZI, 2000) acreditam que a principal preocupação em relação ao osso homógeno é quanto ao seu potencial de transmitir doenças infectocontagiosas. No Brasil, desde 2002, o risco vem reduzindo com a regulamentação e fundamentação do funcionamento dos bancos de ossos, em que se aplicam técnicas adequadas de seleção do doador, processamento e estocagem do material colhido (GARCIA e FEOFILLOF, 1996).

\section{Conclusão}

Conforme avaliação clínica e radiográfica do relato de caso descrito, pode-se concluir que o enxerto homólogo proveniente de bancos de tecidos musculoesqueléticos é uma alternativa viável ao enxerto de osso autógeno, no tratamento de pacientes com perdas ósseas maxilares em área anterior.

\section{Referências}

AMATUZZI, M.M. Banco de tecidos: estruturação e normatização. Revista Brasileira de Ortopedia, v. 35, n. 5, p. 165-172, 2000.

ATWOOD, D.A. Reduction of residual ridges: a major oral disease entity. The Journal of Prosthetic Dentistry, v. 26, p. 266-279, 1971.

CHASE, S.; HERNDON, C. The fate of autogenous and homogenous bone grafts: a hitorical review. Journal of Bone \& Joint Surgery, v. 37, p. 809816, 1955.

CRANIN, A.N.; DEMIRDJAN, E.; DIGREGORIO, $\mathrm{R}$. A comparison of allogeneic and autogenous iliac monocortical grafts to augment the deficient alveolar ridge in a canine model: a clinical study. The Journal of Oral Implantology, v. 29, p. 124131, 2003.
D’AlOJA, C.; D’ALOJA, E.; SANTI, E.; FRANCHINI, M. The use of fresh-frozen bone in oral surgery: a clinical study of 14 consecutive cases. Blood Transfusion, v. 1, p. 82-91, 2011.

D'ALOJA, E.; SANTI, E.; APRILI, G.; FRANCHINI, $M$. Fresh frozen homologous bone in oral surgery: case reports. Cell and Tissue Banking, v. 9, p. 41-46, 2008.

ESPOSITO, M.; GRUSOVIN, M.G.; WORTHINGTON, H.V.; COULTHARD, P. Interventions for replacing missing teeth: bone augmentation techniques for dental implant treatment. Cochrane Database of Systematic Reviews, v. 3, p. 82-87, 2006.

FRIEDLANDER, G. Current concepts review bone grafts. The Journal of Bone and Joint Surgery, v. 69, p. 786-790, 1987.

FUGAZZOTTO, P. Report Of 302 consecutive ridge augmentation procedures: technical considerations and clinical results. The International Journal of Oral \& Maxillofacial Implants, v. 13, p. 358368, 1998.

GARCIA JÚNIOR, I.R.; KUABARA, M.R.; BUENO, R.B.L.; FATTAH, C.M.R.S.; SILVA, P.I.S Avaliação clínica de enxertos ósseos autógenos de crista ilíaca em maxilas atróficas para instalação de implantes ósseointegráveis. Innovations Implant Journal: Biomaterials and Esthetics, v. 2, n. 3, p. 35-40, 2007.

GARCIA, R.J.; FEOFILLOF, E.T. Técnicas de obtenção, processamento, armazenamento e utilização de homoenxertos ósseos, protocolo do banco de ossos da escola paulista de medicina. Revista Brasileira de Ortopedia, v. 31, n. 11, p. 895-903, 1996.

GOMES, K.U.; CARLINI, J.L.; BIRON, C.; RAPOPORT, A.; DEDIVITIS, R.A. Use of allogeneic bone graft in maxillary reconstruction for installation of dental implants. Journal of Oral and Maxillofacial Surgery, v. 66, n. 11, p. 2335-2338, 2006.

GREENSTEIN, G.; GREENSTEIN, B.; CAVALLARO, J.; ELIAN, N.; TARNOW, D. Flap advancement: practical techniques to attain tensionfree primary closure. Journal of Periodontology, v. 80, p. 4-15, 2009. 
LEVANDOWSKY JÚNIOR, N. Utilização do osso alógeno em bloco para aumento de rebordo alveolar: revisão da literatura. Implantnews, v. 5, n. 1, p. $51-57,2008$.

LUPOVICI, J. Revisiting the hopeless ridge: part I: challenging the gold standard. The Compendium of Continuing Education in Dentistry, v. 30, n. 3, p. 130-132, 2009.

MARZOLA, C.; PASTORI, C.M. Enxertos em reconstruções de maxilas atróficas. Revista Eletrônica da Academia Tiradentes de Odontologia, v. 6, n. 2, p. 298-309, 2006.

MAZONETTO, R. Reconstruções em implantodontia: protocolos clínicos para o sucesso e previsibilidade. Nova Odessa: Napoleão, 2009. p. 268.
PETRUNGARO, P.S.; AMAR, S. Localized ridge augmentation with allogenic block grafts prior to implant placement: case reports and histologic evaluations. Implants Dental Baltimore, v. 14, n. 2, p. 139-148, 2005.

POGREL, M.A. The lower border rib graft for mandibular atrophy. Maxillofacial Journal of Oral Surgery, v. 46, p. 95-99, 1988.

RONDINELLI, P.C.; CABRAL, F.P.; FREITAS, E.H.; PENEDO, J.L.; LEITE, J.E.R.; SILVEIRA, S.L.C. Rotina do banco de ossos do hospital de traumatologia e ortopedia do rio de janeiro. Revista Brasileira de Ortopedia, v. 29, n. 6, p. 385-388, 1994.

STEVENSON, S. Biology of bone grafts. The Orthopedic Clinics of North America, v. 30, n. 4, p. 543-552, 1999. 